\title{
Sintesis Senyawaan Seng Secara Elektrolisis
}

\author{
Bahrul Ulum, Fredy Kurniawan, Ita Ulfin \\ Departemen Kimia, Fakultas Ilmu Alam, Institut Teknologi Sepuluh Nopember (ITS) \\ e-mail: fredy@chem.its.ac.id
}

\begin{abstract}
Abstrak-Senyawaan Seng telah disintesis secara elektrolisis. Logam seng (Zn) digunakan sebagai anoda dan katoda. Pengaruh potensial pada pembentukan senyawaan Seng diamati. Produk senyawaan seng dikarakterisasi dengan spektrofotometer UV-Vis. Nilai Absorbansi tertinggi sebesar 0,613 diperoleh pada $\lambda=224 \mathrm{~nm}$ dengan potensial $6 \mathrm{~V}$ dalam natrium sitrat. Nilai absorbansi tertinggi mengindikasikan bahwa senyawaan seng terbentuk paling banyak pada kondisi tersebut.
\end{abstract}

Kata kunci-Elektrolisis, Seng, Natrium Sitrat.

\section{PENDAHULUAN}

$\mathrm{N}$ ANOPARTIKEL telah banyak diaplikasikan diberbagai bidang, salah satunya adalah $\mathrm{Zn}$ nanopartikel. $\mathrm{Zn}$ nanopartikel terdapat dalam beberapa senyawa seperti $\mathrm{ZnO}, \mathrm{ZnO}_{2}$ dan $\mathrm{Zn}(\mathrm{OH})_{2}$. $\mathrm{Zn}(\mathrm{OH})_{2}$ digunakan sebagai prekursor dalam pembuatan senyawa seng lainnya [1]. $\mathrm{Zn}(\mathrm{OH})_{2}$ atau disebut seng hidroksida dapat didekomposisi menjadi $\mathrm{ZnO}$ dan air pada suhu sekitar $125{ }^{\circ} \mathrm{C}$ [2]. Seng hidroksida memiliki struktur kisi yang berbeda seperti tetrahedral, heksagonal dan orthorhombic. Material ini juga dapat dimanfaatkan sebagai bahan absorben [1]. Bahan ini masih jarang dipelajari berdasarkan literatur terbuka [3].

Berbagai metode sintesis Senyawa seng telah digunakan dan dikembangkan, diantaranya pulsed-laser ablation [4], elektrodeposisi [5], kimia basah [2], sonokimia [6] dan hidrotermal [7]. Metode-metode tersebut terbukti menghasilkan produk Senyawa seng, namun membutuhkan relatif memakan waktu dan proses yang rumit. Oleh karena itu diperlukan metode sintesis yang mudah dan cepat untuk mensintesis Senyawa seng.

Metode lain yang dapat dikembangkan untuk sintesis nanopartikel adalah metode elektrokimia. Metode elektrokimia telah diaplikasikan untuk beberapa penelitian, seperti sintesis nanopartikel emas [8], nikel hidroksida [9], Aluminium Oksida [10], timah dioksida [11] dan perak nanopartikel [12]. Efisiensi prosedur ini memberikan beberapa kelebihan termasuk ukuran partikel yang dapat dikontrol, hasil yang baik, kesederhanaan operasional dan ramah lingkungan [13].

Oleh karena itu, sintesis Senyawaan seng dapat menggunakan metode elektrokimia. Penelitian ini dilakukan untuk sintesis Senyawaan seng secara elektrolisis. Logam $\mathrm{Zn}$ digunakan sebagai anoda dan katoda. Proses elektrolisis dilakukan dengan menggunakan larutan elektrolit natrium sitrat. Logam $\mathrm{Zn}$ dielektrolisis dalam larutan natrium sitrat dengan variasi potensial. Produk Senyawaan seng yang diperoleh dikarakterisasi menggunakan Spektrofotometer UV-Vis.

\section{METODOLOGI PENELITIAN}

\section{A. Peralatan dan Bahan}

Peralatan yang digunakan dalam penelitian ini antara lain pemanas (hot plate), neraca analitik Ohaus, power supply, kuvet quartz, magnetic stirrer, gelas kimia, labu ukur, pipet tetes dan pipet ukur. Instrumen yang digunakan untuk karakterisasi Senyawa seng adalah spektrofotometer UVVis GENESYS 10S. Bahan-bahan yang digunakan dalam penelitian ini antara lain aqua demineralisasi (Brataco), natrium sitrat (Merck) dan logam Zn.

\section{B. Metode}

Senyawaan seng disintesis secara elektrolisis menggunakan logam seng ( $\mathrm{Zn}$ ) sebagai katoda dan anoda. Elektrolisis dilakukan dengan variasi potensial, yaitu 2 hingga 8 volt dalam larutan elektrolit Natrium Sitrat untuk mengetahui pengaruh potensial. Setelah elektrolisis dihentikan, kedua elektroda dilepas dari sel elektrolisis, dikeringkan pada suhu kamar dan timbang untuk mengetahui perubahan massa sebelum dan sesudah elektrolisis. Larutan yang diperoleh didinginkan pada suhu ruang kemudian dikarakterisasi menggunakan spekrofotometer UV-Vis GENESYS 10S.

\section{HASIL DAN PEMBAHASAN}

Pembentukan senyawaan seng dapat diketahui dengan perubahan warna yang terjadi pada larutan. Warna larutan berubah secara bertahap dari tidak bewarna hingga biru pudar. Nanopartikel dikarakterisasi menggunakan UV-Vis. Kondisi optimum dalam penelitian ini terjadi pada potensial $6 \mathrm{~V}$ dengan nilai absorbansi 0,613 pada panjang gelombang $224 \mathrm{~nm}$. Hasil UV-Vis ditunjukkan pada Gambar 1. Semakin besar potensial yang digunakan maka semakin banyak pula logam seng yang terlarut. Ini menunjukkan bahwa potensial berpengaruh terhadap jumlah seng yang terlarut yang disajikan dalam Tabel 1.

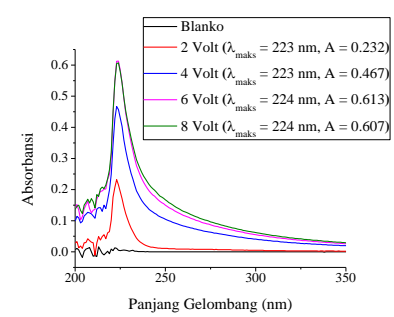

Gambar 1. Spektra UV-Vis Senyawaan Seng Variasi Potensial 
Tabel 1.

Massa Logam Seng (Zn) yang Terlarut dalam Senyawaan Seng Variasi Potensial

\begin{tabular}{ccc}
\hline \hline No. & Potensial $(\mathrm{V})$ & Massa $($ gram $)$ \\
\hline 1. & 2 & 0,0039 \\
2. & 4 & 0,0088 \\
3. & 6 & 0,0104 \\
4. & 8 & 0,0112 \\
\hline \hline
\end{tabular}

\section{KESIMPULAN}

Berdasarkan hasil dan pembahasan dapat disimpulkan bahwa senyawaan Seng dapat disintesis secara elektrolisis dengan larutan elektrolit natrium sitrat dan elektroda $\mathrm{Zn}$. Kondisi optimum untuk sintesis terjadi pada potensial $6 \mathrm{~V}$. Nilai absorbansi pada kondisi ini adalah 0,613 pada panjang gelombang $224 \mathrm{~nm}$.

\section{DAFTAR PUSTAKA}

[1] P. P. . Patnaik, Handbook of Inorganic Chemicals. New York: The McGraw-Hill Companies, Inc, 2003.

[2] M. Y. Ghotbi, "Synthesis and characterization of nano-sized $\varepsilon$ $\mathrm{Zn}(\mathrm{OH}) 2$ and its decomposed product, nano-zinc oxide," J. Alloy Compd., pp. 420-422, 2010 .

[3] A. R. M. . Hussein M.Z.B., Ghotbi M.Y., Yahaya A.H., "Solid State Sci," vol. 11, pp. 368-374, 2009.

[4] M. M. and K. N. Liang C., Shimizu Y., "Preparation of layered zinc hydroxide/ surfactant nano composite by pulsed-laser ablation in a liquid medium, Chem. Mater," vol. 16, pp. 963-965, 2004.
Ying Lu, Zhen-Hong Mai, "Electrochemical Synthesis of Highly Oriented Layered Zinc Hydroxide with Intercalated pAminobenzoic Acid," J. Phys. Chem. C, vol. 112, pp. 38003804, 2008.

[6] and pezeshkpour V Ghaedi M., Naghiha R., Jannesar R. dehghanian N., Mirtamizdoust B., "Antibacterial and antifungal activity of flower extracts of Urtica dioica, Chamaemelum nobile and Salvia officinalis: Effects of $\mathrm{Zn}(\mathrm{OH}) 2$ nanoparticles and $\mathrm{Hp}$ 2-minh on their property," J. Ind. Eng. Chem., vol. 32, pp. 353359,2015

[7] A. S. and H. A. Mosayebi Elham., "Synthesis of nanostructured and microstructured $\mathrm{ZnO}$ and $\mathrm{Zn}(\mathrm{OH}) 2$ on activated carbon cloth by hydrothermal and microwave-assisted chemichal bath deposition method," Superlattices Microstruct., vol. 81, pp. 226232,2015

[8] F. Qurrotul H, H., dan Kurniawan F., "Optimasi Konsentrasi NaSitrat dan Pengaruh Potensial Dalam Sintesis Emas Nanopartikel," ITS, 2011.

[9] dan S. Budipramana, Y., Ersam, T., Kurniawan, F., "Sythesis Nickel Hidroxide by Electrolysis at High Voltage," ARPN J. Eng. Appl. Sci., vol. 9, no. 11, pp. 2074-2077, 2014.

[10] K. M. M, "Sintesis Nanopartikel Aluminium Oksida dengan Metode Elektrokimia," Institut Teknologi Sepuluh Nopember 2016.

[11] dan K. F. Rahmi R, "Synthesis of SnO2 Nanoparticles by High Potential Electrolysis," Bull. Chem. React. Eng. Catal., vol. 12, no. 2, pp. 281-286, 2017.

[12] K. F. Sitti Rahmah., "Electrochemical Methods for Manufacturing Silver Nanoparticles. Advances in Social Science, Education and Humanities Research, volume 100," in 5th South East Asia Development Research (SEA-DR) International Conference, 2017.

[13] A. Anandgaonker, P., Kulkarni, G., Gaikwad, S., dan Rajbhoj, "Synthesis of $\mathrm{TiO} 2$ nanoparticles by electrochemical method and their antibacterial application," Arab. J. Chem., 2015. 